\title{
MINING FOR GOLD: LEARNING ANALYTICS AND DESIGN FOR LEARNING: A REVIEW
}

\author{
Claire Goode, Ana Terry, Hugh Harlow and Rachel Cash
}

\section{INTRODUCTION}

Learning analytics (LA) has been a key development in learning design (LD) and technology-enhanced learning over the past decade. Mining data relating to the user experience of technology can help educators understand when learners access sites and resources, how they access them, and what they access. This can inform the next iteration of course design, maximise the value of interactions with students, and enable institutions to develop learner-centred courses and improve learner success, all of which may set them apart from the mass of competition in online and/or blended learning. In this article, we first consider the definition and purpose of LA, specifically in a tertiary education context, then review the literature in this fast-moving field, focusing on three core areas.

\section{BACKGROUND}

Learning analytics is frequently defined as "the measurement, collection, analysis and reporting of data about learners and their contexts for purposes of understanding and optimizing learning and the environments in which it occurs" (Siemens, 20II). This includes not only looking at data retrospectively, in order to improve LD and teaching and assessment practices, for example, but also analysing data to predict future behaviours and recognise potential problems so that they can be addressed. In other words, LA should provide "actionable intelligence for learners and teachers" (Learning Analytics Community Exchange, 2014). In 2013, the NMC Horizon Report (Johnson et al., 2013) identified LA as an area of emerging technology that would impact significantly on higher education, with an expected time-to-adoption horizon of two to three years; by 2019 , the same report (Alexander et al., 2019) suggested the time-to-adoption horizon had dropped to one year or less.

Over time, the student body in tertiary education is becoming "increasingly diverse in age, cultural and socioeconomic background, motivation and general experience with technology" (Corrin et al., 2016, p. 7). An upsurge in the use of technology tools in teaching (particularly relevant during a global pandemic, with teachers and learners all working from home at different times) means that there is more and more data available for analytics. One advantage of this is that, as Lockyer et al. (2013) highlight, LA data can be used to provide evidence to inform pedagogical decisions, ultimately enhancing learning effectiveness and learner success. A multi-institutional collaborative project in Australia (Corrin et al., 2016), for example, focused on "how learning analytics can be delivered to [tertiary] teachers in meaningful ways [to] help improve teaching and learning practices" (p. 5). Having said this, the terminology associated with LA - including 'big data,' 'data mining,' 'machine learning,' 'business intelligence' and 'clickstream analytics' - is not only varied, but can often be too technical. If we want teachers to become involved and engaged in LA, it needs to be seen simply as a way in which data can help them answer questions about learning, or to address common challenges in learning and teaching (Gunn et al., 2017).

Previously, while data gathering was already occurring in educational institutions, it was perhaps not being valued for the wealth of information that it provided. In 2010, for instance, Dawson et al. reported that " $t$ the information 
on student behaviour captured by the [Learning Management System (LMS)] has been ... rarely interrogated and adopted beyond basic load and tool usage" (p. 121), and that "access to these data has traditionally been removed from the learning context, and has only recently begun to expand into the scholarship of teaching and learning" (p. 124). Long and Siemens (201 I, p. 32) would agree: "Higher Education ... has traditionally been inefficient in its data use ... Something must change." A report from the United Kingdom's (UK) Higher Education Commission (Shacklock, 2016) sets out II recommendations, including a call for a sector-wide LA strategy (p. I3), and "clear ethical policies and codes of practices" (p. 39). Five years on, it is timely to consider how the field of LA has progressed, how educational institutions are implementing the use of LA in policy and practice, what insights have been gained, and what further recommendations can be made.

\section{SUPPORTING DESIGN FOR LEARNING}

Echoing the call for LA terminology and purpose to be transparent, Kennedy et al. assert that it can be difficult for educators "to make sense of learning analytics data without a clear understanding of the pedagogical intent behind the design of learning tasks set for students" (2014, p. 436). They go on to argue that linking LD with LA tools and techniques will lead to a "better understanding of how analytics can be most usefully applied, interpreted, and actioned by academic staff" (p. 436). Mangaroska and Giannakos (2019) agree, seeing learning analytics and learning design as two complementary fields within educational technology. Seeing LA in action, then, is key to successful integration into ongoing practice.

Mor et al. (2015) look at how LD, LA and teacher inquiry combine "to form a virtuous circle" (p. 22I), each informing and improving the others. As they explain, "within this circle, learning analytics offers a powerful set of tools for teacher inquiry, feeding back into improved learning design. Learning design provides a semantic structure for analytics, whereas teacher inquiry defines meaningful questions to analyse" (Mor et al., 2015, p. 22I). Similar interactions are suggested in Bakharia et al.'s (2016) conceptual framework (Figure I), consisting of five dimensions of LA - temporal analytics, comparative analytics, cohort dynamics, tool specific analytics, and contingency and intervention support tools - in which "the teacher plays a crucial role in bringing context to the analysis and making decisions on the feedback provided to learners, as well as the scaffolding and adaptation of the learning design" (2016, section 4, para I).

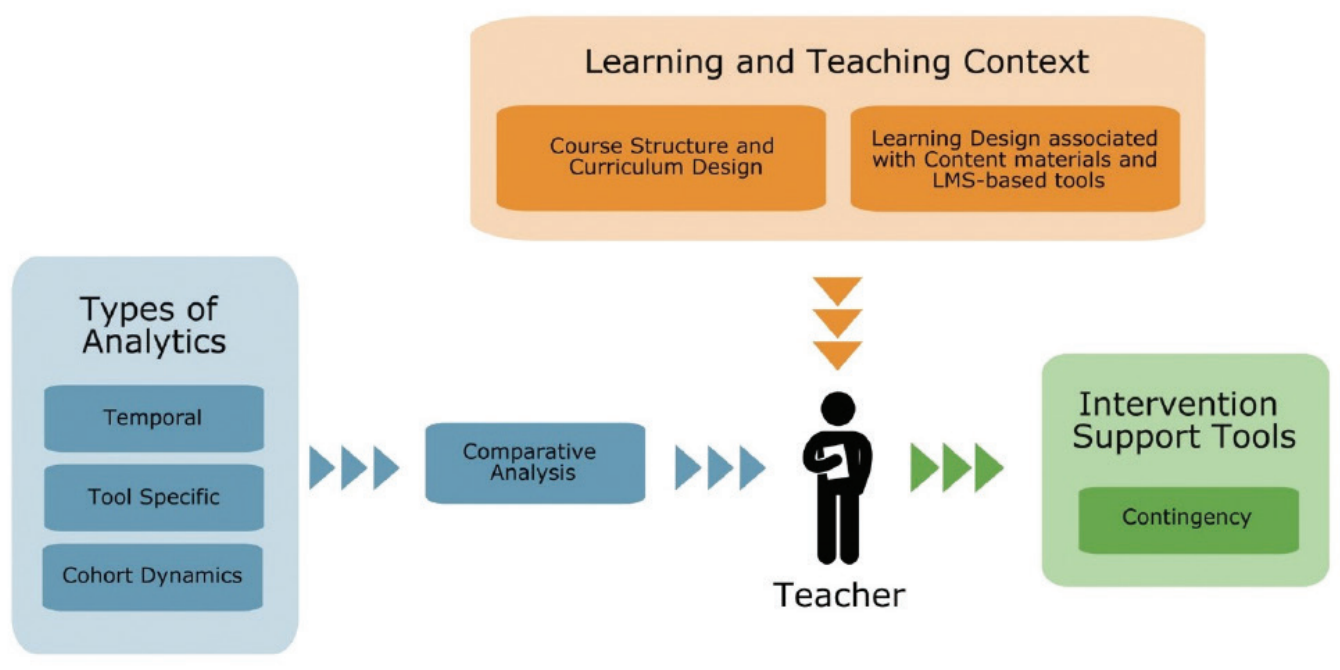

Figure I. The learning analytics for learning design conceptual framework (Bakharia et al., 2016). 
They suggest that this framework "bridg[es] the gap between learning design and learning analytics while establishing a platform to support enquiry-based evaluation and scaffolding of learning activities" (Bakharia et al., 2016, p. 336), but it is unclear whether any subsequent research has been undertaken to implement this.

Gunn et al.'s (2017) Learning analytics-learning design framework (Figure 2) aims to:

prompt teachers to focus on very specific questions at different points during the regular teaching cycle. It can also be used as an entry point to make sense of more complex learning analytics conceptual frameworks as teachers gain confidence and begin to incorporate learning analytics data into their daily practice. (2017, p. 12)

In addition, the framework may help different stakeholders reflect on and develop appropriate policies and strategic plans, and could be used as part of professional development conversations to build teachers' confidence around the use and benefits of learning analytics.

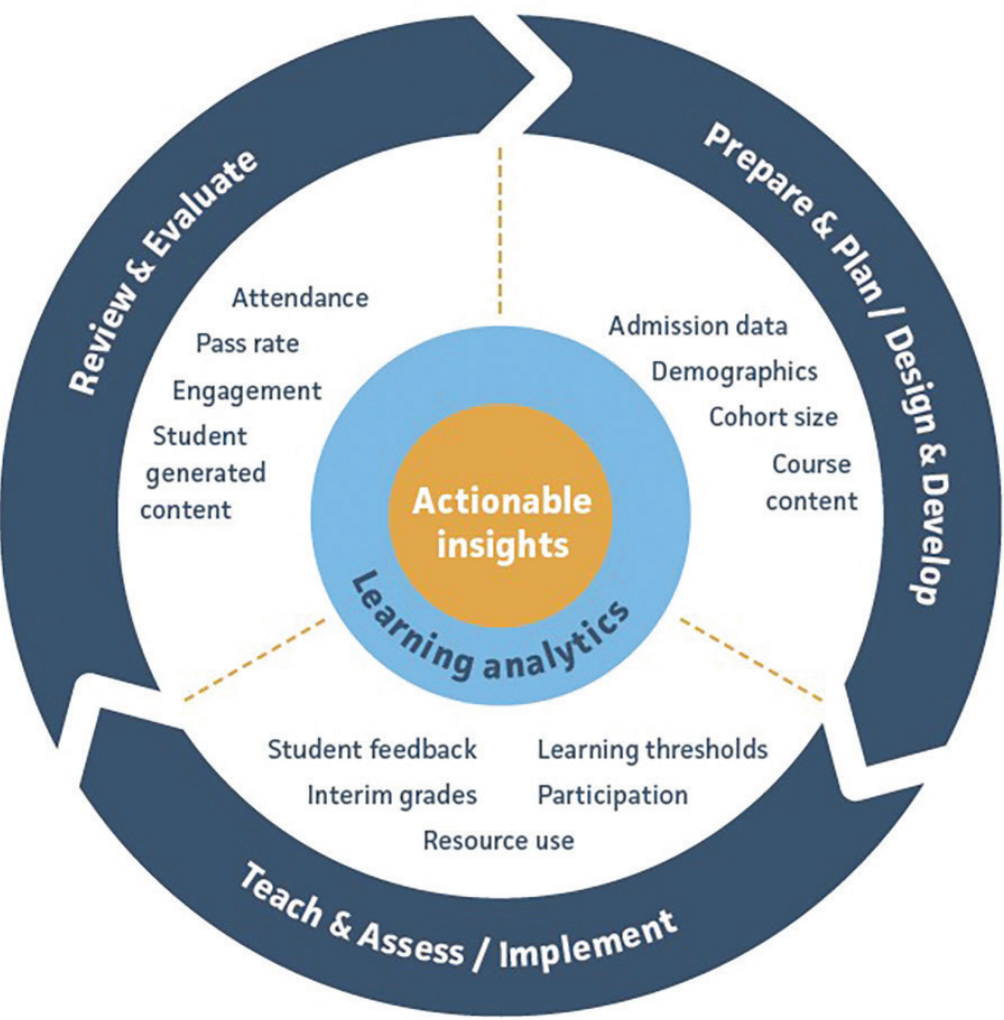

Figure 2. The learning analytics-learning design framework (Gunn et al., 2017).

To what extent, though, do the expectations of the learning designer align with the real user experience? After all, as Gunn et al. (2017, p. 5) emphasise, "Linking learning analytics to learning design is seen as a critical step towards evidence-based course design." Ahn et al. (2019) report on the use of human-centred design as a way of managing any misalignment between LA dashboard design and its intended use. Dollinger and Lodge (2018), again drawing attention to the "persistent issue" (p. 97) of the mismatch between interface design and user 
engagement, call for "a perspective shift for learning analytics to be not only 'about learners' but also with learners" (2018, p. 97), and emphasise the need for students and educators to be involved in the co-creation of LA design and processes. Neither learning designers, educators nor researchers should 'assume' to know what learners want without inviting them into the discussion. Designing in partnership and in context brings with it multiple advantages over designing in isolation (Ahn et al., 2019; Dollinger \& Lodge, 2018). While teachers may wish to see data comparisons across their cohorts, for instance, some learners may find this demotivating (Schumacher \& Ifenthaler, 2018). Furthermore, "[s]tudents expect highly developed learning analytics systems, combining the functions of various programs, allowing personalization, showing the results of diverse analyses, and giving recommendations for further learning"' (Schumacher \& Ifenthaler, 2018, p. 75). We return to the topic of user concerns and challenges in the next section.

For Hernández-Leo et al. (2019), despite the clear synergies between LA and LD, there is only "limited and fragmented work exploring the use of data analytics to support learning design" (p. I40). Following a systematic literature review of their own, they concluded that there are "no models capturing the variety of connections that exist between learner/educator data, the design, co-design processes and the implementation of learning tasks" (p. 140). As a result, they propose an "Analytics Layers for Learning Design" (AL4LD) framework (Figure 3), articulating three differentiated but interdependent layers of data analytics to support informed decision-making in LD by addressing the following design questions:

- What are the effects of the learning design on the actual learning experiences? (learning analytics layer)

- What are the design decisions and related aspects that characterise the learning designs? (design analytics layer)

- How do educators (and related roles) co-design for learning? (community analytics layer)

\section{“Analytics Layers for Learning Design" Framework}

\section{Awareness, understanding, reflection and impact on how, what and with which effects practitioners design for learning}

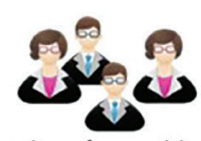

Community of practitioners and related roles

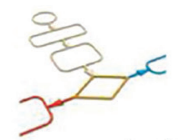

Learning Design (LD) tools

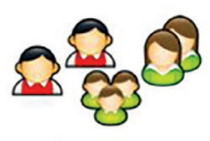

Learners (and other participants) experiencing learning designs

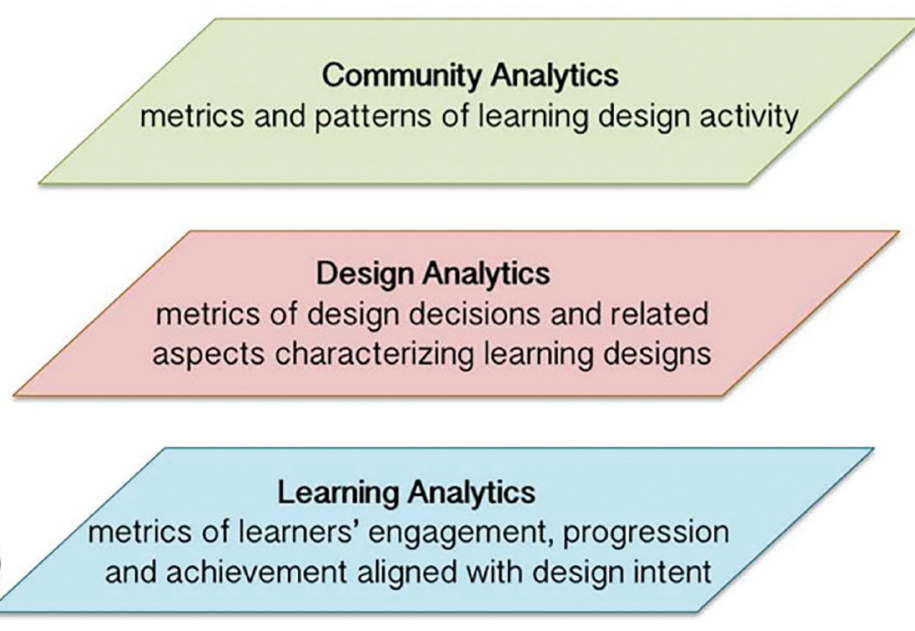

Figure 3. Graphical representation of the AL4LD framework (Hernández-Leo et al., 2019). 
Interactions between these layers capture the relevant synergies, such as aligning the design intent with a learner's activity patterns, making it easier to interpret LA. In turn, the authors suggest that, if LA are aligned with the design intent, then teachers can consider the data to improve LD in future iterations.

Holmes et al. (2019) used a "Learning Analytics for Learning Design" methodology to investigate the implementation of LD in an online distance-learning context. Using LA, they researched common patterns of learning activities among different LD practitioners, how learners' behaviour varies across different patterns of learning activities, and which patterns of LD activities have the most potential for improving learner outcomes. Their study focuses on two key innovations: combinations or patterns of LD activities, by means of a cluster analysis (which revealed that different patterns of LD were associated with statistically significant differences in learner behaviour); and applying social network analysis to the clusters to further clarify the relationships between learning activities within each cluster.

Similarly, Mangaroska and Giannakos (2019), in their review of how LA and LD intersect, explored "what learning analytics have been used to inform learning design decisions, and what were the main design approaches researchers embraced" (2019, p. 531) over a seven-year period (2010-17). They concluded that a tendency to view LA as purely quantitative can lead to "a misalignment between the information generated by learning analytics tools with the needs, problems, and concerns that teachers have regarding learning designs and learning activities (2019, p. 527), and recommend that "future research should consider developing a framework on how to capture and systematize learning design data and follow what learning design choices made by educators influence subsequent learning activities and performances over time" (2019, p. 531).

In summary, there needs to be close collaboration between key stakeholders - including learner, learning designer and teacher - in any LA initiative, given the need for understanding both its context and application.

\section{PLAYING TO THE GALLERY?}

As the use of LA has grown, there has been an increase in critical analysis and discussion of both the learner's expectations of $L A$, their mistrust and the potential for this to further isolate learners already feeling disenfranchised or struggling with their studies. Several strands contribute to this unease, including concerns around surveillance, coersion, lack of agency and a sense of performativity.

Selwyn (2019), for example, considers how LA can influence what students do and how they may respond in ways which in fact counter what LA has been designed to do - to support learning. Selwyn highlights that, "while not designed to be 'evaluatory' per se, learning analytics technologies are nevertheless being implemented in school and university contexts shaped by evaluation, testing, measuring, ranking, and performance comparison" (p.13). With such high stakes, compounded by the sense of being analysed (as the name 'analytics' itself reinforces), learner behaviour may be influenced by LA to 'play the game' or 'please' the indicators.

Prinsloo (2019) critically examines this potential through a social cartography of data analytics by scrutinising LA and describing it as an actant - an agent which creates the learner's narrative rather than supporting it. He provides evidence to suggest $L A$ is not only representational, but is also increasingly performative and political, and argues that an LA system defines success and creates "norms" by constructing a reality which is presented as truth. Like Selwyn (2019), Prinsloo proposes that one consequence of this is that students learn the rules and regulations of their context and perform to comply within them.

Part of Prinsloo's analysis focuses on reviewing what is gathered in the way of data and its relevance - for example, data on age, gender, race and marital status. Prinsloo suggests that these "zombie categories" (2020, pp. 619-620) may limit our understanding of difference and perpetuate "norms." Selwyn (2019, p. 13) agrees: "A central concern here relates to the reproduction of existing social inequalities as well as the generation of new forms of inequality through data-driven processes." Beer (20I8), too, contends that data is not objective; all data is 
modelled and constructed, shaped and evaluated based on the designer's and/or analyst's ideas and assumptions. Indeed, "data and algorithms can contain and perpetuate bias" (University of Edinburgh, 20I8, p. 2). This is one area, then, in which both critical reflection and transparency are essential.

As well as potentially placing learners into predetermined silos, the assumptions and dominant discourses of LA designers have shed little light on what influences learner engagement. "Analytics cannot give a complete picture of an individual's learning" (University of Wollongong, 2020, p. 7). As a result, LA has the potential to 'colonise' learning as students realise they must both conform with and perform to dominant narratives of what their learning should look like. In essence, then, critics argue that LA lacks a nuanced awareness of or ability to capture and represent the complexities of individual learners and/or their learning experiences.

These findings again support the need to engage students in the decision-making process about LA (Roberts et al., 2016; Slade \& Prinsloo, 2013). However, few studies have gone beyond 'surface' collaboration, focusing on user experience preferences (personalised dashboards, progress bars, and so on) as opposed to understanding the individual needs of learners.

\section{DATA, DISTRUST AND DECISIONS}

Alongside these concerns, awareness has also grown of the ethical considerations surrounding the collection and use of student data (Prinsloo \& Slade, 2017; Slade \& Prinsloo, 2013). Viberg et al. (2018) suggest that the use of LA "poses moral and policy issues for students' privacy [and] there are crucial questions that need to be addressed to ensure that [Learning Analytics] are commensurate with students' privacy and autonomy" (p. 108). One potential consequence of these concerns is the risk that LA adoption may be hindered because of "fear induced by ethics and privacy issues [which] can easily lead to misunderstandings and distrust in institutions" (Tsai et al, 2018, p. 7, citing Drachsler \& Greller, 2016). Several authors (including Slade \& Prinsloo, 2013; Tsai et al., 2018) suggest that informed consent is essential in establishing trust. As Welsh and McKinney explain:

informed consent means that: (a) clear and accurate information is provided about what data is or may be collected, why and how it is collected, how it is stored and how it is used; and (b) agreement is freely given to the practice(s) described. (2015, p. 590)

Alongside this is the need to give students the ability to 'opt out' of a Learning Analytics programme. Selwyn (2019, p. 16), however, goes a step further, suggesting that "it might be more appropriate for learning analytics systems to be designed on an 'opt-in' basis." This is echoed by New Zealand's Tertiary Education Commission (2021, p. 21), who recommend that consent "should be opt-in rather than opt-out," to ensure complete transparency.

The establishment and implementation of clear principles and policies is an essential step in an organisation's adoption of LA, in order to "guide the stakeholders and encourage ethical use of data within an educational system where power is unequally distributed among different stakeholders" (Tsai et al., 20 I8, p. 6). The University of Edinburgh, for instance, places an emphasis on "ensur[ing] learning analytics projects and implementations are conducted according to defined ethical principles and align with organisational strategy, policy and values" $(2018$, p. 3). Tsai et al. $(2018$, p. 6), who contributed to the development of the European SHEILA framework, agree, saying that "in order to establish analytics sustainability, it is imperative that [educational organisations] align the adoption of $L A$ with their institutional vison and goals."

Policies should also ensure that data is used "only in the context and purpose for which it was provided" (Prinsloo \& Slade, 2017, p. 53). Without clear guidelines, as Selwyn (2019) contends, there is the risk of "mission-creep" in which data is "co-opted into broader institutional purposes" (p. 13). Policies should therefore ensure transparency in how the organisation "collect[s] and use[s] data, with whom [they] share it, where consent applies, and where responsibilities for the ethical use of data lie" (University of Edinburgh, 20I8, p. 2). Examples of this transparency 
can be seen in the University of Edinburgh's documentation (2018, p. 3), which states that "data generated from learning analytics will not be used to monitor staff performance, unless specifically authorised following additional consultation," and in the University of West London's policy (2016, p. 3), indicating that LA "will not be used as a form of student assessment or to influence the marking of any student assessments."

Policies also need to recognise that any presentation of data, and decisions made from that data, can have unforeseen negative consequences, regardless of intention. Schumacher and Ifenthaler (20I8), for example, draw attention to students suffering "demotivating consequences due to visualization of poor performances or comparisons with fellow students" (p. 70), while the University of West London (2016, p. 3) states that LA "must not be used to limit the [institution's] or the students' expectations of what they can achieve." Just as students may learn to 'play the game' and work the LA system, Selwyn (2019, p. 13) suggests that careless use of data might mean that

[t]eachers will work to "second guess" what the system will reward; for example, "teaching to the algorithm" in a similar manner to the well-established phenomenon of "teaching to the test." When working in educational settings overlaid with analytics, it is inevitable that teachers and students will focus on the things being analysed.

It is reassuring to see that the Tertiary Education Commission's comprehensive Oritetanga learner analytics ethics framework (202I) draws on many of the principles previously outlined in the literature and highlighted here, and incorporates considerations unique to New Zealand's bicultural context.

\section{CONCLUSION}

The Tertiary Education Commission's framework comes at a time of increased interest in LA. If institutions are considering developing their own LA programmes, the framework has arrived in time to inform the associated policies and practices and, along with other international examples (including the SHEILA project in Europe), outlines the steps for establishing successful and ethical LA programmes.

These programmes require policies and strategies which are developed in collaboration with all stakeholders, before jumping feet-first into the data. It is not about creating 'ideal' learner behaviour. Instead, the 'gold' within learning analytics is found when it informs learning design to help educators and institutions provide better learning experiences.

Claire Goode has over 20 years' experience teaching in a variety of contexts, including prison education, university and foundation programmes, principally in New Zealand, France and the United Kingdom. She was awarded a Senior Fellowship with the Higher Education Academy in June 2018, and is particularly interested in teacher development.

(D) https://orcid.org/0000-0002-2255-6523

Ana Terry is a learning and teaching specialist in the Learning and Teaching Development team at Otago Polytechnic. She has over 20 years' experience teaching in a variety of contexts, including university and polytechnic programmes in New Zealand, the US, Malaysia and China.

(1) https://orcid.org/0000-0001-9437-9522

Hugh Harlow spent 8 years teaching sound engineering and music production at a tertiary level in London before joining the Learning and Teaching Development team at Otago Polytechnic in 2017. He finds his current role rewarding, working alongside colleagues from a wide range of disciplines, incorporating innovations and new technologies into learning and teaching.

(10) https://orcid.org/0000-0002-2893-4054 
Rachel Cash is a learning and teaching specialist in the Learning and Teaching Development team at Otago Polytechnic. Since obtaining her degree in information communication technologies in 2004, she has worked in a variety of online development roles for the Tertiary Accord of New Zealand (TANZ) and Otago Polytechnic.

(D) https://orcid.org/0000-0002-4558-9985

\section{REFERENCES}

Ahn, J., Campos, F., Hays, M., \& DiGiacomo, D. (2019). Designing in context: Reaching beyond usability in learning analytics dashboard design. Journal of Learning Analytics, 6(2), 70-85. https://doi.org//0.18608/jla.2019.62.5

Alexander, B., Ashford-Rowe, K., Barajas-Murphy, N., Dobbin, G., Knott, J., McCormack, M., Pomerantz, J., Seilhamer, R., \& Weber, N. (2019). Educause horizon report: 2019 higher education edition. EDUCAUSE. https://library.educause.edu/-/media/ files/library/2019/4/20 I9horizonreport.pdf?la=en\&hash=C8E8D444AF372E705FAIBF9D4FF0DD4CC6F0FDD I

Bakharia, A., Corrin, L., de Barba, P., Kennedy, G., Gašević, D., Mulder, R., Williams, D., Dawson, S., \& Lockyer, L. (2016, April). A conceptual framework linking learning design with learning analytics. In LAK 'I6: Proceedings of the sixth international conference on learning analytics \& knowledge (pp. 329-338). https://doi.org/l0.1/45/2883851.2883944

Beer, D. (2018). The data gaze. Sage.

Corrin, L., Kennedy, G., de Barba, P. G., Lockyer, L., Gašević, D., Williams, D., Dawson, S., Mulder, R., Copeland, S., \& Bakharia, A. (2016). Completing the loop: Returning meaningful learning analytic data to teachers. Sydney: Office for Learning and Teaching. https://melbourne-cshe.unimelb.edu.au/_data/assets/pdf_file/0006/2083938/Loop_Handbook.pdf

Dawson, S., Heathcote, L., \& Poole, G. (2010). Harnessing ICT potential: The adoption and analysis of ICT systems for enhancing the student learning experience. International Journal of Educational Management, 24(2), II6-128. https://doi. org/10.1108/09513541011020936

Dollinger, M., \& Lodge, J. M. (2018). Co-creation strategies for learning analytics. Proceedings of the 8th International Conference on Learning Analytics and Knowledge (97-101). Sydney, Australia. https://doi.org//0.1 I45/3170358.3170372

Gunn, C., McDonald, J., Donald, C., Milne, J., \& Blumenstein, M. (2017). Building an evidence base for teaching and learning design using learning analytics. Ako Aotearoa. https://ako.ac.nz/assets/Knowledge-centre/NPF-I5-008-Building-an-Evidence-Basefor-Teaching-and-Learning-Design-Using-Learning-Analytics-Data/RESEARCH-REPORT-Building-an-evidence-base-forteaching-and-learning-design-using-learning-analytics.pdf

Hernández-Leo, D., Martinez-Maldonado, R., Pardo, A., Muñoz-Cristóbal, J.A., \& Rodríguez-Triana, M. J. (2019). Analytics for learning design: A layered framework and tools. British Journal of Educational Technology, 50(I), I39-I52. https://doi. org/l0.1 III/bjet.12645

Holmes, W., Nguyen, Q., Zhang, J., Mavrikis, M., \& Rienties, B. (2019). Learning analytics for learning design in online distance learning. Distance Education, 40(3), 309-329. https://doi.org/I0.1080/01587919.2019.1637716

Johnson, L., Adams Becker, S., Cummins, M., Estrada, V., Freeman, A., \& Ludgate, H. (2013). NMC Horizon Report: 2013 Higher Education Edition. The New Media Consortium. https://library.educause.edu/resources/2013/2/20 I3-horizon-report

Kennedy, G., Corrin, L., Lockyer, L., Dawson, S., Williams, D., Mulder, R., Khamis, S., \& Copeland, S. (2014, November 24-26). Completing the loop: Returning learning analytics to teachers. In B. Hegarty, J. McDonald, \& S.-K. Loke (Eds.), Rhetoric and reality: Critical perspectives on educational technology. https://ascilite.org/conferences/dunedin20/4/files/concisepapers/76Kennedy.pdf

Learning Analytics Community Exchange. (2014, December 15). What are learning analytics? http://www.laceproject.eu/faqs/ learning-analytics/

Lockyer, L., Heathcote, E., \& Dawson, S. (2013). Informing pedagogical action: Aligning learning analytics with learning design. American Behavioural Scientist, 57(10), 1439-1459. https://doi.org//0.1177/0002764213479367

Long, P., \& Siemens, G. (20II). Penetrating the fog: Analytics in learning and education. EDUCAUSE Review, 46(5), 30-40. https:// er.educause.edu/ /media/files/article-downloads/ermII5I.pdf\%20

Mangaroska, K., \& Giannakos, M. (2019). Learning analytics for learning design: A systematic literature review of analyticsdriven design to enhance learning. IEEE Transactions on Learning Technologies, 12(4), 516-534. https://doi.org/l0.1/09/ TLT.2018.2868673

Mor, Y., Ferguson, R., \& Wasson, B. (2015). Editorial: Learning design, teacher inquiry into student learning and learning analytics: A call for action. British Journal of Educational Technology, 46(2), 221-229. https://doi.org/I0.1 I I I/bjet. I 2273 
Prinsloo, P. (2019). A social cartography of analytics in education as performative politics. British Journal of Educational Technology, 50(6), 2810-2823. https://doi.org/10.1111/bjet.12872

Prinsloo, P. (2020). (Re)centring students in learning analytics: In conversation with Paulo Freire. Assessment \& Evaluation in Higher Education, 45(4), 617-628. https://doi.org/10.1080/02602938.2019.1679716

Prinsloo, P., \& Slade, S. (2017). Ethics and learning analytics: Charting the (un)charted. In C. Lang, G. Siemens, A. Wise, \& D. Gašević (Eds.), Handbook of learning analytics (pp. 49-57). Society for Learning Analytics Research (SoLAR).

Roberts, L. D., Howell, J. A., Seaman, K., \& Gibson, D. C. (2016). Student attitudes

toward learning analytics in higher education: "The Fitbit version of the learning world." Frontiers Psychology, 7, I-II. https://doi. org/10.3389/fpsyg.2016.01959

Schumacher, C., \& Ifenthaler, D. (2018). Features students really expect from learning analytics. Computers in Human Behavior, 78, 397-407. https://doi.org/10.1016/j.chb.2017.06.030

Selwyn, N. (2019). What's the problem with learning analytics? Journal of Learning Analytics, 6(3), II-19. https://doi.org//0.18608/ jla.2019.63.3

Shacklock, X. (2016). From bricks to clicks: The potential of data and analytics in higher education. Higher Education Commission. https://www.policyconnect.org.uk/hec/research/report-bricks-clicks-potential-data-and-analytics-higher-education

Siemens, G. (201I, August 5). Learning and academic analytics. http://www.learninganalytics.net/?p=|3|

Slade, S. \& Prinsloo, P. (2013). Learning analytics: Ethical issues and dilemmas. American Behavioral Scientist, 57(I0), I5I0-1529. https://doi.org/l0.1177/0002764213479366

Tertiary Education Commission. (202I). Analysing student data: Ōritetanga learner analytics ethics framework. https://tec.govt.nz/ assets/Oritetanga/Learner-Analytics/Analysing-Student-Data-Oritetanga-Learner-Analytics-Framework.pdf

Tsai, Y-S., Moreno-Marcos, P. M., Jivet, I., Scheffel, M., Tammets, K., Kollom, K., \& Gašević, D. (20I8). The SHEILA framework: Informing institutional strategies and policy processes of learning analytics. Journal of Learning Analytics, 5(3), 5-20. https:// doi.org/l0.18608/jla.2018.53.2

University of Edinburgh. (2018). Learning analytics principles and purposes. https://www.ed.ac.uk/academic-services/policiesregulations/learning-and-assessment/learning-analytics/principles

University of West London. (2016). Learning analytics policy. https://www.uwl.ac.uk/sites/default/files/Departments/About-us/ Web/PDF/policies/uwl_learning_analytics_policy_final.pdf

University of Wollongong. (2020, May). Learning analytics data use policy. https://documents.uow.edu.au/about/policy/alphalisting/ UOW242448.html

Viberg, O., Hatakka, M., Bälter, O., \& Mavroudi, A. (2018). The current landscape of learning analytics in higher education. Computers in Human Behavior, 89, 98-110. https://doi.org/10.1016/j.chb.2018.07.027

Welsh, S., \& McKinney, S. (2015). Clearing the fog: A learning analytics code of practice. In T. Reiners et al. (Eds.), Globally connected, digitally enabled. Proceedings of the 32nd Annual Conference of the Australasian Society for Computers in Learning in Tertiary Education (ASCILITE 20I5), 29 November-2 December 2015, Perth, Western Australia (pp. 588-592). http:// research.moodle.net/80/ 